\title{
Using English Songs: an Enjoyable and Effective Approach to ELT
}

\author{
Chunxuan Shen \\ School of Foreign Languages \\ Zhejiang Gongshang University \\ Xuezheng Street 18, Xiasha Higher Education Zone \\ Hangzhou 310018, China \\ Tel: 86-571-2800-2084Ｅ-Mail: nosia@163.com
}

\begin{abstract}
How can ELT be made enjoyable and effective? One feasible pedagogical application is to integrate English songs into ELT. Song, a combination of music and lyrics, possesses many intrinsic merits, such as a kaleidoscope of culture, expressiveness, recitability and therapeutic functions, which render it an invaluable source for language teaching. This paper provides theoretical arguments and practical support for using English songs in ELT.
\end{abstract}

Keywords: English songs, English language teaching, Enjoyable, Effective

\section{Introduction}

English language teaching (ELT) in China has for quite a long time followed the traditional path-teaching vocabulary and grammar textbooks, cramming students with a considerable amount of exercises and then evaluating their accomplishments through consecutive exams. It is no surprise that EFL learners view English language learning as insipid and an unconquerable obstacle. In fact, ELT can be implemented in a relaxed and enjoyable way by using English songs in EFL classes.

Songs have been an amusing companion for human beings for as long as or even longer than we can speak. As an integral part of our language experience, it can be of great value to foreign language teaching. And the many-faceted merits songs possess may enrich and activate our foreign language class. Georgi Lozanov incorporates music into his teaching method-Suggestopedia, for music is instrumental in creating a relaxing and comfortable environment, which can propel language learning (Larsen-Freeman, 1985). Besides music, another indispensable element of songs is lyrics which serve as a direct genuine source of teaching materials in foreign language classes, so why should songs be overlooked by the teachers? There have been abundant researches abroad on songs as an authentic teaching resource in language teaching (Maley, 1997; Eken, 1996; Gaston, 1968; Geoff, 2003), but a paucity of such studies are reported in China. This paper endeavors to demonstrate the value of English songs in ELT and meanwhile reports several specific teaching activities as serious attempts to work it out in EFL classrooms.

\section{Songs should be used in ELT for their own merits}

Being a combination of music and language, songs have innumerable virtues that deserve our attention. Their richness in culture and themes, their idiomatic and poetic expressions, their therapeutic functions and so on makes them an impeccable tool for language teaching.

\subsection{A kaleidoscope of culture}

"Language expresses, embodies and symbolizes cultural reality" (Kramsch, 2000, p.3). Language and music are interwoven in songs to communicate cultural reality in a very unique way. English songs endow the English native speakers with an opportunity to put across their own culture. Black American's call for equality and respect, the legends of the American West, celebration of western festivals and people's attitudes toward love, friendship and marriage all find expression in the lines and rhythmic melodies of the songs.

\subsection{Expressiveness}

Songs are highly expressive. Some convey love and emotions; some tell a memorable and moving story; some embody one's dreams and ideals; and some reminisce about the golden past. Songs are abundant in themes and expressions which will echo in the learner's heart. "Acquisition of automatic language skills depends on rich, meaningful, repeated exposure to comprehensible input without awareness" (Bolitho et al., 2003, p.253).

\subsection{Recitability}

Lyrics are characterized by the use of rhythms, conversational speech and poetic expressions. For example, the 
following song Vincent sings of an artist's loneliness, inner contradiction and of the tranquil and perpetual starry night in the very poetic and rhymed lines. The other song entitled Sing, however, is of quite different style with simple words, colloquial sentences and an upbeat tune.

\section{Vincent}

Starry starry night

Paint your palette blue and grey

Look out on a summer's day

With eyes that know the darkness

in my soul

Shadows on the hills

Sketch the trees and the daffodils

Catch the breeze and the winter chills

In colors on the snowy linen land

Sing

Sing! Sing a song.

Sing out loud. Sing out strong.

Sing of good things, not bad,

Sing of happy, not sad.

Sing, sing a song.

Make it simple to last your whole life long.

Don't worry that it's not good enough

For anyone else to hear.

Just sing, sing a song.

Learners are likely to be attracted by these beautiful and poetic, or colloquial and lucid lyrics, which will be easily recited and long remembered. Singing a song by heart is more delightful and meaningful than rote learning. Many people can not help recalling the songs learned in their early years, even when they only vaguely remember the old melodies and some fragments of the lyrics.

\subsection{Therapeutic functions}

In general, the foremost function of songs is to provide relaxation and recreation. It is quite common that when people are tired, they will sit back and listen to a piece of music or they may hang out with friends to sing in Karaoke, clubs or bars. Music has the power to soothe people's emotions, refresh their minds and to unlock their creativity. Gaston (1968) has pointed out that music has several therapeutic functions, such as promoting self-esteem through increased self-satisfaction in musical performance and using the unique potential of rhythm to energize and bring order.

\section{How can English songs facilitate English language learning}

"Language teaching can be defined as the activities which are intended to bring about language learning" (Stern, 1983, p.21). Hence, whatever theory of language teaching should starts from the learning process or the learner's perspective.

\subsection{Psychological implications}

"The concept of learning, as it is understood today, has been greatly influenced by the psychological study of the learning process..." (ibid, p.18). This section demonstrates the effectiveness of integrating English songs into ELT from the theory of human brain, which is the headquarter of language processing.

\subsubsection{MI and listening to English songs}

The theory of Multiple Intelligence (MI), proposed and elaborated by Gardner (1993), points out that there are a number of distinct types of intelligence possessed by each individual in varying degrees. In accordance with MI, human intelligence is categorized into at least nine primary types: verbal/linguistic intelligence, mathematical/logical intelligence, visual/spatial intelligence, body/kinesthetic intelligence, musical/rhythmic intelligence, interpersonal intelligence, intrapersonal intelligence, naturalist intelligence and existential intelligence, all of which are not isolated and irrelevant, but interdependent on and complementary with each other. Therefore, it is inappropriate to explore only one type of intelligence in EFL learning. Verbal/linguistic intelligence, musical/rhythmic intelligence, interpersonal 
intelligence, body/kinesthetic intelligence and even more may contribute to developing and complementing a learner's linguistic competence and enhance his ability of learning a foreign language. Listening to English songs is of great value to tap the learner's linguistic potentials through enchanting melodies, varying rhythms and image-evoking lyrics, which appeal to multidimensional development of human intelligence.

\subsubsection{Hemisphere functioning in language learning}

Research on psycholinguistics reveals that songs can activate language acquisition and learning in both hemispheres of the human brain (Carroll, 2000; Larsen-Freeman and Long, 2000; Williams and Burden, 1997). Through psychologists' persistent study on ear and hemisphere functioning differences, findings come out that right ear, which leads to left hemisphere (LH), takes conspicuous advantages over left ear for speech stimuli, so "the LH does seem to possess an innate and highly specialized linguistic mechanism" which assumes the major responsibility of analytic processing of language (Carroll, 2000, p.349). However, the right hemisphere's important function in language processing can not be ignored. Left ear, which leads to right hemisphere, is keener to nonverbal sound such as melodies and emotional colors of the message. Songs enter the human brain - from left ear to right hemisphere - in a rather different way from our speech and thus can stimulate language learning in the right hemisphere, whose involvement in language processing become more active in eliciting the overall meaning and processing formulaic speech (Ellis, 1985). "Formulaic Speech consists of expressions which are learned as unanalysable wholes and employed on particular occasions" (Lyons, 1968, p.177).

\subsection{Stimulation of affective learning by songs}

Using English songs in EFL classrooms can successfully bring about affective learning through providing a harmonious classroom atmosphere, reducing students' anxiety, fostering their interests and motivating them to learn the target language. Students will regard English songs as part of entertainment rather than work and thus find learning English through songs amusing and relaxed.

\subsubsection{The Affective Filter Hypothesis}

In 1982, "Dulay et al. suggested that the use of filter depends upon affective factors such as the learner's motivation, attitude and emotions" (Ellis, 1985, p.297). And later Krashen developed the Affective Filter Hypothesis based on Dulay's point of view. Krashen (1985) argued that affective learning will occur when the affective filter is weak. When the learner is in such an affective state as highly motivated, self-confident and at ease, the filter will be weak and allow in plenty of input, which means a positive attitude toward learning and the optimum state of language learning are present. On the contrary, the filter will become stronger when the learner is haunted with low motivation, lack of self-confidence and high anxiety. In that case, the learner is not ready for language acquisition or learning. The Affective Filter Hypothesis suggests that an ideal teacher should be capable of providing a classroom atmosphere conducive to motivating, encouraging his students and lessening their anxiety if there's any.

\subsubsection{Anxiety}

Anxiety, associated with negative feelings, such as upset, tension, frustration, self-doubt and fear, would impede language learning (Larsen-Freeman, 2000). Students beyond puberty are more apt to be affected by anxiety in learning a foreign language. Therefore, to minimize the amount of anxiety in foreign language learners becomes crucial to successful language learning.

\subsubsection{Arousal of motivation by English songs}

Motivation is a vital element in affective learning. Williams and Burden (1997, p.129) deciphered motivation as "a state of cognitive and emotional arousal, which leads to a conscious decision to act, and which gives rise to a period of sustained intellectual and/or physical effort in order to attain a previously set goal (or goals)". Motivation can be triggered by either internal causes like the learner's interest, enthusiasm and desire or by such external influences as peer pressure.

Many English songs, especially pop songs are quite popular among the Chinese young people, such as Jingle Bells, Yesterday Once More, Right Here Waiting, My Heart will Go on and Big Big World. For one thing, these English songs employ the themes that appeal to young people, like holiday celebration, memories of childhood, love and friendship; and for another, many students desire to learn these English songs, because they want to model themselves on the Hollywood stars and singers or improve their status among the peers. The greater their desire is, the faster they learn. When they are learning fast and continuously making progress, they will be more confident, highly motivated and devoted to the learning task.

\subsubsection{Effects of Affective learning}

Affective learning is also effective learning. In the light of psycholinguistics, affective engagement with language can "stimulate a fuller use of the resources of the brain", rekindle "neural paths between areas of brain" and deepen the multidimensional processing of language (Bolitho et al., 2003, p.256). Through affective learning, the learner's capacity 
for learning will be expanded and whereby unexpected results will be produced.

\subsection{Songs can promote language awareness}

Language awareness is "a means of helping learners to help themselves". The result of raising language awareness "will not just be language use, but also language use which is more sensitive to issues of culture, identity and equity" (ibid, p.254). Songs serve as the very source of such target language use that helps to promote students' language awareness in learning English as a foreign language.

\subsubsection{Definition of language awareness}

"Language awareness is a mental attribute which develops through paying motivated attention to language in use, and which enables language learners to gradually gain insights into how languages work" (ibid, p.251). Tomlinson (1994, p.123) looks upon language awareness as "dynamic and intuitive", which is "gradually developed internally by the learner".

\subsubsection{Songs and language awareness}

As for the students who are earnest to learn or sing English songs, listening to English songs can prompt them to ask questions about the language. They have to grab the skills of speaking the English language before they can sing the songs on their own. Hence, they are encouraged to probe how every sound is pronounced and how all the sounds are chained together, thereby attaining growing insights into the way the English language functions to convey meaning. In this process, the difficulties that learners have encountered in singing English songs will enable them to notice the gap between their actual performance in the target language and the proficiency of the native singers. "This noticing can give salience to a feature, so that it becomes more noticeable in future input, and thereby contributes to the learner's psychological readiness to acquire that feature" (Bolitho et al., 2003, p.252).

In addition, although most students regard listening to as well as learning English songs as entertainment, they are also learning implicitly and unconsciously, which is a much more pleasant and efficient way to promote language awareness than mechanically memorizing tedious course-books of vocabulary and grammar. "Language awareness is not taught by the teacher or by the course-book; it is developed by the learner. Language awareness is an internal, gradual, realization of the realities of language use" (ibid, p.252).

\section{How to utilize English songs in EFL classrooms}

As is demonstrated above, MI theory, hemisphere functioning, language awareness and the intrinsic merits that songs possess are all in support of utilizing English songs in ELT. The next thing that calls for our attention is how to bring about the educational value of English songs in EFL classrooms. Some specific practices adopted by the researcher are recommended here as initial attempts to integrate English songs into teaching various aspects of language skills-listening, speaking, vocabulary, grammar and writing in college English teaching.

\subsection{In listening}

A good listening comprehension lays the corner-stone for developing other skills in foreign language learning. But it is also the most difficult among all the language skills for novice to master. While listening to a native speaker, in most cases we find their speech running smoothly just like a river, even not fast, so that EFL learners may fail to catch them. A justification for this is that learners have for too long been accustomed to speak word by word without reducing, liaison, loss of explosion and so on which are quite common in a native speaker's ordinary speech. Native speakers talk word by word only under special circumstances, like talking to a baby. For example, few native speakers will say "not

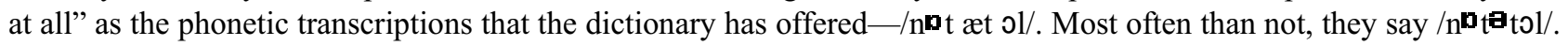
Not only are the consonants and the following vowels glued together as we call liaison, but /t/ are also voiced, which makes it sound like $/ \mathrm{d} /$, and $/ \mathfrak{t} /$ is reduced to $/ \mathbf{a} \mathrm{t} /$.

Listening to English songs will prepare EFL learners to the genuine English language they are to be faced with. Teachers can devise special exercises to assist students in improving their listening comprehension. A gap-fill task as follows can be used to help students notice and absorb the phonetic reality in native English speakers' speech. Take the popular song Big Big World as an example.

\section{Big Big World}

I can see the first falling it's all yellow and nice

It's so very cold like the way I'm feeling

I'm a big big in a big big ; it's not a big big thing if you leave me.

But__ do do feel that do do will, you much, you much... it's now raining and falling from my eyes

Why did it have to , why did it all have to 


I'm a big big __ in a big big___ ; it's not a big big thing if you leave me.
But__ do do feel that___ do do will, __ you much, __ you much...
I have

But when I__ my___ you're gone...

(keys: leaf, outside, inside, girl, world, I, I, miss, miss, Outside, tears are, happen, end, girl, world, I, I, miss, miss, my arms, warm, open, eyes)

The lyrics are first presented to students certain parts removed. After enjoying the song, students are asked to fill in the blanks with the words they catch. The words in the blanks are taken off not randomly but with intent. Most of them have undergone slight changes in sound, so it is not easy for students to recognize them in listening. The changes obey the phonological rules which are subconsciously employed by native speakers in ordinary speeches but are often neglected by EFL learners. For example, the word "leaf" in the first blank has lost its final consonant /f/ because the succeeding word "falling" begins with /f/. The word "end" in the second blank of the sixth line is mistaken by many students for "when", even though they are confused by the meaning and structure of "why did it all have to when". The reason is that boundary insertion has occurred between the two words "to" and "end". A glide /w/ inserts between the rounded vowel /u/ and the unrounded vowel /e/ (Chomsky, 1968). Additionally, on most occasions final /d/ can not be heard because of its loss of explosion. That's why many students make a mistake here.

This exercise can be of great help because only when the natural pronunciation and all the phonological rules become internalized in the learners can they gradually catch up with the native speakers' speech. The internalization of these phonological rules by the EFL learners certainly demands the coordination of the second step-speaking.

\subsection{In Speaking}

Songs can be used to teach natural pronunciation efficiently. Native singers' pronunciation provides a model for EFL learners. We can easily find songs sung by either American, British, Canadian or Australian singers and let learners choose which pronunciation they would like to imitate. By repeatedly listening to and learning these songs, students will gradually correct their errors and achieve a more native-like pronunciation.

Moreover, to sing an English song well also demands familiarity with a number of above-mentioned phonological rules. For instance, liaison, loss of explosion, assimilation, voicing, deletion, insertion and so on are the most common phenomena that occur nearly in every English song. To describe these phonological rules in linguistic terminologies could be an abstract and delicate task, but English songs serve as a medium through which these rules can be made concrete and accessible. EFL learners will get familiar with and internalize them through repetition and imitation. The experimental class the researcher taught reveals that students who always listen to English songs pay more deliberate attention to pronunciation, phonological rules, stress and intonation than the others and thus pronounce more correctly and speak English more fluently.

\subsection{In Memorizing vocabulary, structure and grammar}

When coming across an impressive song, most learners are eager to take a further step - to understand what the singers are expressing and to sing it by themselves. With such a motivation, learners will feel surprised they can remember all the words that appear in the lyrics, even difficult ones. The song in the famous Disney cartoon "Lion King"-Can you Feel the Love Tonight-always rings in learners' ears. Some words and phrases that appear in its lyrics are difficult indeed, like surrender, vagabond, twisting kaleidoscope, star-crossed voyager, and wide-eyed wanderer. But to teach these words in a melodic context appears easier and more effective.

The nature of songs is fairly repetitive and consistent. For example, Lemon Tree-a very familiar pop song provides ample opportunities for students to focus on the study of the present progressive tense in English grammar. 'I'm sitting here in a boring room", "I'm wasting my time", “I'm hanging around, I'm waiting for you", "I'm driving around in my car. I'm driving too fast, I'm driving too far", "I'm turning my head up and down, I'm turning turning turning turning turning around", "I'm stepping around in a desert of joy" and so forth. After listening to this song, students will easily memorize these simple sentences, tend to use them in their own conversation and even correctly produce their own sentences of the present progressive tense.

Songs are not always composed of simple sentence structure or grammar. For instance, the following song Promises Don't Come Easy serves as a paragon for teaching the subjunctive mood, one of the most difficult and confusing grammatical points for students in learning English. For instance, "I should have known all along", but "I", in the lyrics, actually didn't realize at the beginning that there was something wrong in his or her love relationship. This part presents students with a vivid picture of the inner world of a person in love, in which they can easily capture the mood and content the song writer intends to convey, thereby comprehending and absorbing the grammatical point of subjunctive mood unconsciously. 


\section{Promises Don't Come Easy}

I should have known all along

there was something wrong

I just never read between the lines

then I woke up one day and found you way

leaving nothing but my heart behind

what can I do to make it up to you

Listening to English songs easily embed new vocabulary and grammatical structures in learner's both conscious and unconscious memory. Its unexpected teaching effects will startle you!

\subsection{In Creative Writing}

Serious writing may bore EFL learners. So why not occasionally make writing fun in class by inventing something new? In creative writing of songs, students are encouraged to create their own lyrics by following the same tune and imitating the format of the lyrical lines of the original song. In the researcher's class, students were quite interested in such new forms of writing assignment and many turned in surprisingly wonderful and imaginative works. The following version "Baby, Don't Cry" was rewritten by one of the students from the song "Que Sera, Sera".

\section{Baby, Don't Cry}

When I was just a little girl

I dreamed of beauty

I dreamed of fame

I wanna marry a rich handsome man

But reality drove me mad

"Oh, baby, don't cry,"

My mother told me that,

"The future will not be so bad.

Oh, baby, don't cry.

Like a bird you'll fly."

\section{Que Sera Sera}

When I was just a little girl,

I asked my mother,

"What will I be?

Will I be pretty, will I be rich?"

Here's what she said to me:

"Que Sera, Sera.

Whatever will be, will be.

The future's not ours to see.

Que Sera, Sera.

What will be, will be."

Obviously, the new version mimics the original song in form such as both encompass a conversation between the mother and her daughter and then end in the mother's soothing words. However, the student brings in something new in content. The new version focuses on the daughter's disillusionment of childhood dreams rather than on the naive inquiry about the future when she was only a little girl. Use of parallel structure, idiomatic expressions and rhymes in the new version Baby, Don't Cry all manifest the student's creativity, imagination as well English writing ability.

Therefore, writing lyrics by imitation might be an effectual way of digging out EFL learners' creativity in language. The right song will arouse their empathy, stimulate their inspiration and light their passion to express their experiences and emotions in the same way.

\section{Conclusion}

The specific teaching practices of utilizing English songs in reinforcing different aspects of the students' language skills are based on the researcher's own experiment in college English classes. After finishing the text analysis of each unit, which usually takes two weeks, about thirty minutes are spent on different classroom activities concerning English songs described above. Therefore, in 68 teaching hours of the whole semester for each class, 4 teaching hours in all are spared for immersing the students in English songs. The following table is a comparison of the students' total score for the college English course, which is mainly comprised of self-listening tests, final oral test and final written exam, as is prescribed by the university's teaching agenda for college English. The classes the researcher is teaching are two different classes of the same year in the same College, one is Electronics and the other is Communication Engineering, whose average academic performance in National Entrance Exam and in the previous semesters is at a similar level. The table suggests that using English songs in college English classes will not weaken but reinforce the effect of teaching.

\section{Insert Table 1 Here}

Note: Class 1 is the controlled group following the same teaching agenda as other classes in the university without the English songs teaching application; and class 2 is the experimental group to whom the English songs approach is deliberately applied. The two classes use the same teaching facilities, have the same English teacher and go through the same teaching procedures except this difference. P in the table represents the correlation of the two classes' scores, 
which is significant when $\mathrm{P}$ is less than 0.05 (i.e. $\mathrm{P}<0.05$ ).

In conclusion, using English songs in ELT can be justified on the grounds that it will emancipate full mental and affective power in language learning and promote language awareness. Listening to songs can knock down the learner's psychological barriers, such as anxiety, lack of self-confidence and apprehension as well as fire the learner's desire to grasp the target language. Pedagogically, effective learning consists in active engagement with language. English songs are wonderful materials in this respect. EFL learners are easily moved and motivated by the singers, the music, the variety of rhythm, and the popular themes. Furthermore, songs are comprehensible, enjoyable, authentic and full of language we need in real life. These intrinsic merits that songs possess also recommend themselves as effective materials of instruction in EFL classrooms. If used properly by the teacher, English songs are excellent means whereby EFL learners will cultivate interests and high motivation in the target language as well as develop linguistic intelligence and language awareness.

\section{References}

Bolitho, R., Carter, R., Hughes, R., Ivanic, R., Masuhara, H. \& Tomlinson, B. (2003). Ten questions about language awareness, ELT Journal 57/3: 251-259.

Carroll, D.W. (2000). Psychology of Language. Beijing: Brooks/Cole/Thomson Learning Asia.

Chomsky, N \& Halle, M. (1968). The Sound Pattern of English. New York: Harper \& Row.

Eken, D. K. (1996). Ideas for using pop songs in the English language classroom. English Teaching Forum 34: 234-41.

Ellis, R. (1985). Understanding Second Language Acquisition. Shanghai: Shanghai Foreign Language Education Press.

Gardener, H. (1983). Frames of Mind. New York: Basic Books.

Gardener, H. (1993). Multiple Intelligences: The Theory in Practice. New York: Basic Books.

Gaston, E.T. (1968). Music in Therapy. New York: Macmillan.

Geoff, P.S. (2003). Music and mondegreens: extracting meaning from noise. ELT Journal 57/2: 113-121

Kramsch, C. (2000). Language and Culture. Shanghai: Shanghai Foreign Language Education Press.

Krashen, S. (1985). The Input Hypothesis: Issues and Implications. London: Longman.

Larsen-Freeman, D. \& Long, M. H. (2000). An Introduction to Second Language Acquisition Research. Shanghai: Shanghai Foreign Language Education Press.

Larsen-Freeman, D. (1985). Techniques and Principles in Language Teaching. England: Oxford University Press.

Lyons, J. (1968). Introduction to Theoretical Linguistics. Cambridge: Cambridge University Press.

Maley, A. (1997). Poetry and Song as Effective Language-learning Activities. In Wigla M. R. Interactive Language Teaching. Cambridge: Cambridge University Press. Pp. 93-109.

Stern, H.H. (1983). Fundamental Concepts of Language Teaching. Shanghai: Shanghai Foreign Language Education Press.

Tomlinson, B. (1994). Pragmatic awareness activities. Language Awareness. 3/3: 119-129.

Williams, M., \& Burden, R. L. (1997). Psychology for Language Teaching. Cambridge: Cambridge University Press.

Table 1. A comparison of students' total score for college English between two classes

\begin{tabular}{|l|l|l|l|}
\hline Class & Mean & Std. Deviation & P \\
\hline Class 1 $(\mathrm{N}=26)$ & 70.07 & 9.10 & .02 \\
\cline { 1 - 3 } Class 2 $(\mathrm{N}=31)$ & 76.65 & 7.52 & \\
\hline
\end{tabular}

